University for Business and Technology in Kosovo

UBT Knowledge Center

Oct 28th, 9:00 AM - Oct 30th, 5:00 PM

\title{
Generalization of strong convergence theorem in CAT(0) spaces
}

Alba Troci

Mediterranean University

Follow this and additional works at: https://knowledgecenter.ubt-uni.net/conference

Part of the Social and Behavioral Sciences Commons

\section{Recommended Citation}

Troci, Alba, "Generalization of strong convergence theorem in CAT(0) spaces" (2016). UBT International Conference. 30.

https://knowledgecenter.ubt-uni.net/conference/2016/all-events/30

This Event is brought to you for free and open access by the Publication and Journals at UBT Knowledge Center. It has been accepted for inclusion in UBT International Conference by an authorized administrator of UBT Knowledge Center. For more information, please contact knowledge.center@ubt-uni.net. 


\title{
Generalization of strong convergence theorem in $\mathrm{CAT}(0)$ spaces
}

\author{
Alba Troci \\ Department of Mathematics and Informatics, Faculty of Business Mediterranean \\ University.
}

\begin{abstract}
The aim of this paper is to give the generalization condition of T-Ciric quasi contractive mapping. Also to study the generalization of strong convergence theorem of modified S-iteration process for Ciric quasi contractive operator in the framework of CAT(0) spaces based on new generalized condition for T-Ciric quasi contractive mapping. Our results extend and generalize many known results from the previous work given in the existing literature (see $[1,6]$ ).
\end{abstract}

\section{Introduction and Preliminaries}

CAT $(0)$ space. A metric space $\mathrm{X}$ is a $\mathrm{CAT}(0)$ space if it is geodesically connected and if every geodesic triangle in $\mathrm{X}$ is at least as 'thin' as its comparison triangle in the Euclidean plane. It is well known that any complete, simply connected Riemannian manifold having nonpositive sectional curvature is a CAT(0) space. Other examples include Pre-Hilbert spaces (see [3]), R-trees (see [11]), Euclidean buildings (see [12]), the complex Hilbert ball with a hyperbolic metric (see [13]), and many others. For a thorough discussion of these spaces and of the fundamental role they play in geometry, we refer the reader to Bridson and Haefliger [3]. Fixed point theory in CAT(0) spaces was first studied by Kirk (see [1,2]). He showed that every nonexpansive (single-valued) mapping defined on a bounded closed convex subset of a complete $\mathrm{CAT}(0)$ space always has a fixed point. Since then, the fixed point theory for single-valued and multi-valued mappings in CAT(0) spaces has been rapidly developed, and many papers have appeared.

Let $(X, d)$ be a metric space. A geodesic path joining $x, y \in X \mathrm{x} \in \mathrm{X}$ is a map $c:[0, d(x, y)]$ $\rightarrow X$ such that:

- $c(0)=x$

- $\quad c(d(x, y))=y$

- $\mathrm{d}\left(\mathrm{c}\left(t_{1}\right), c\left(t_{2}\right)\right)=\left|t_{1}-t_{2}\right| \quad, \forall t_{1}, t_{2} \in[0, d(x, y)]$.

The image $\alpha$ of $\mathrm{c}$ is called a geodesic (or metric) segment joining $\mathrm{x}$ and $\mathrm{y}$. We say $\mathrm{X}$ is (i) a geodesic space if any two points of $\mathrm{X}$ are joined by a geodesic and (ii) uniquely geodesic if there is exactly one geodesic joining $\mathrm{x}$ and $\mathrm{y}$ for each $\mathrm{x}, \mathrm{y} \in \mathrm{X}$, which we will denote by $[\mathrm{x}$, $\mathrm{y}$, called the segment joining $\mathrm{x}$ to $\mathrm{y}$. 
Book of Proceedings

International Conference on Social Sciences, Humanities, and other sciences

Comparision triangle

A geodesic triangle $\Delta(p, q, r)$. in a geodesic metric space $(\mathrm{X}, \mathrm{d})$ consists of three points in $p, q, r \in X$ and a geodesic segment between each pair of vertices $[p, q],[q, r],[r, p]$.

A comparison triangle for the geodesic triangle $\Delta(p, q, r)$ in $(\mathrm{X}, \mathrm{d})$ is a triangle $\bar{\Delta}(\bar{p}, \bar{q}, \bar{r}) \subset$ $\mathbb{R}^{2}$ such that:

- $d(p, q)=d(\bar{p}, \bar{q})$

- $\quad d(q, r)=d(\bar{q}, \bar{r})$

- $d(r, p)=d(\bar{r}, \bar{p})$

Definition of CAT $(0)$ space

Let $(X, d)$ be a geodesic metric space. It is called $C A T(0)$ space if for any geodesic triangle $\Delta \in X$ and $x, y \in \Delta$ :

$$
d(x, y) \leq \mathrm{d}(\bar{x}, \bar{y}) \quad \mathrm{ku} \bar{x}, \bar{y} \in \bar{\Delta}
$$

\section{Main Result}

\subsection{Generalization of T-Ciric Quasi Contraction Mapping}

Let $X$ be a CAT(0) space and $S, T: X \rightarrow X$ be two mappings. Then $S$ is called $T$-Ciric quasi contraction mapping if it satisfies the following condition:

(1.1)

$d(T S x, T S y) \leq h \max \left\{d(T x, T y), \frac{d(T x, T S x)+d(T y, T S y)}{2}, \frac{d(T x, T S y)+d(T y, T S x)}{2}\right\}$

$(T C Q C)$

for all $x, y \in X$ and $0<h<1$.

Then the condition (TCQC) can be generalized as follows:

$d(T S x, T S y) \leq h \max \left\{d(T x, T y), \frac{d(T x, T S x)+d(T y, T S y)}{m}, \frac{d(T x, T S y)+d(T y, T S x)}{m}\right\}$

$(T C Q C)^{*}$

for all $x, y \in X$ and $0<h<\frac{m}{2}$. 


\subsection{Proof}

Each of the conditions $\left(T Z_{1}\right)-\left(T Z_{3}\right)$ implies $(T C Q C)^{*}$

$\left(T Z_{1}\right) \quad d(T S x, T S y) \leq a d(T x, T y) \leq a \frac{m}{2} d(T x, T y), \quad 0<a<1, m \geq 2$.

$\left(T Z_{2}\right) \quad d(T S x, T S y) \leq b[d(T x, T S x)+d(T y, T S y)], \quad 0<b<\frac{1}{2}$

$\left(T Z_{3}\right) \quad d(T S x, T S y) \leq c[d(T x, T S y)+d(T y, T S x)], \quad 0<c<\frac{1}{2}$

implies:

$d(T S x, T S y) \leq \max \left\{a \frac{m}{2} d(T x, T y), b m \frac{d(T x, T S x)+d(T y, T S y)}{m}, c m \frac{d(T x, T S y)+d(T y, T S x)}{m}\right\}$

$\leq h \max \left\{d(T x, T y), \frac{d(T x, T S x)+d(T y, T S y)}{m}, \frac{d(T x, T S y)+d(T y, T S x)}{m}\right\}$

when $h=\max \left\{a \frac{m}{2}, b m, c m\right\}$.

$0<a<1 \Rightarrow 0<a \frac{m}{2}<\frac{m}{2}$

$0<b<\frac{1}{2} \Rightarrow 0<b m<\frac{m}{2} \quad \Rightarrow 0<h<\frac{m}{2}$.

$0<c<\frac{1}{2} \Rightarrow 0<c m<\frac{m}{2}$

\section{Generalization of strong convergence theorems in CAT(0) spaces}

\subsection{Theorem}

Let $C$ be a nonempty closed convex subset of a complete CAT(0) space. Let $S, T: C \rightarrow C$ be two commuting mappings such that $T$ is continuous, one-to-one, sub-sequentially convergent and $S: C \rightarrow C$ is a T-Ciric quasi-contractive operator satisfying (TCQC)* 
with $0<h<\frac{m}{2}, m \geq 2$. Let $\left\{x_{n}\right\}$ be defined by the iteration scheme (1.8) [1]. If $\sum_{n=1}^{\infty} \alpha_{n}=\infty, \sum_{n=1}^{\infty} \alpha_{n} \beta_{n}=\infty, \sum_{n=1}^{\infty} \alpha_{n} \beta_{n} \gamma_{n}=\infty$, then $\left\{T x_{n}\right\}$ converges strongly to $T u$, where $u$ is the fixed point of the operator $S$ in $C$.

\subsection{Proof}

From Theorem 1.1 [1], we get that $S$ has a unique fixed point in $C$, say $u$. Consider $x, y \in C$ . Since $S$ in a T-Ciric quasi-contractive operator satisfying (TCQC) ${ }^{*}$, then if

$$
\begin{aligned}
d(T S x, T S y) & \leq \frac{h}{m}[d(T x, T S x)+d(T y, T S y)] \\
& \leq \frac{h}{m}[d(T x, T S x)+d(T y, T x)+d(T x, T S x)+d(T S x, T S y)],
\end{aligned}
$$

Implies

$$
\left(1-\frac{h}{m}\right) d(T S x, T S y) \leq \frac{h}{m} d(T x, T y)+\frac{2 h}{m} d(T x, T S x),
$$

Which yields (using the fact that $0<h<\frac{m}{2}, m \geq 2$ )

$$
d(T S x, T S y) \leq\left(\frac{h / m}{1-h / m}\right) d(T x, T y)+\left(\frac{2 h / m}{1-h / m}\right) d(T x, T S x) .
$$

If

$$
\begin{aligned}
d(T S x, T S y) & \leq \frac{h}{m}[d(T x, T S y)+d(T y, T S x)] \\
& \leq \frac{h}{m}[d(T x, T S x)+d(T S x, T S y)+d(T y, T x)+d(T x, T S x)]
\end{aligned}
$$

Implies

$$
\left(1-\frac{h}{m}\right) d(T S x, T S y) \leq \frac{h}{m} d(T x, T y)+\frac{2 h}{m} d(T x, T S x)
$$

Which also yields (using the fact that $0<h<\frac{h}{m}, m \geq 2$ ) 


$$
d(T S x, T S y) \leq\left(\frac{h / m}{1-h / m}\right) d(T x, T y)+\left(\frac{2 h / m}{1-h / m}\right) d(T x, T S x) .
$$

Denote

$$
\begin{aligned}
& \delta=\max \left\{h, \frac{h / m}{1-h / m}\right\}=h, \\
& L=\frac{2 h / m}{1-h / m} .
\end{aligned}
$$

Thus, in all cases,

$$
\begin{aligned}
d(T S x, T S y) & \leq \delta d(T x, T y)+L d(T x, T S x) \\
= & h d(T x, T y)+\left(\frac{2 h / m}{1-h / m}\right) d(T x, T S x) .
\end{aligned}
$$

holds for all $x, y \in C$.

Also from (TCQC) ${ }^{*}$ with $y=u=S u$, we have

$$
d(T S x, T S u) \leq h \max \left\{d(T x, T u), \frac{d(T x, T S x)}{m}, \frac{d(T x, T S u)+d(T u, T S x)}{m}\right\}
$$

$\leq h \max \left\{d(T x, T u), \frac{d(T x, T u)+d(T u, T S x)}{m}, \frac{d(T x, T S u)+d(T u, T S x)}{m}\right\}$

$$
\begin{aligned}
& =h \max \left\{d(T x, T u), \frac{d(T x, T u)+d(T u, T S x)}{m}\right\} \\
& \leq h d(T x, T u) .
\end{aligned}
$$

Now (4.21) gives

$$
\begin{aligned}
& d\left(T S x_{n}, T u\right) \leq h d\left(T x_{n}, T u\right) . \\
& d\left(T S y_{n}, T u\right) \leq h d\left(T y_{n}, T u\right) . \\
& d\left(T S z_{n}, T u\right) \leq h d\left(T z_{n}, T u\right) .
\end{aligned}
$$

Using (1.8),(2.6) and Lemma 1.1(ii) [1], we have

$$
d\left(T z_{n}, T u\right)=d\left(\gamma_{n} T S x_{n} \oplus\left(1-\gamma_{n}\right) T x_{n}, T u\right)
$$




$$
\begin{aligned}
& \leq \gamma_{n} d\left(T S x_{n}, T u\right)+\left(1-\gamma_{n}\right) d\left(T x_{n}, T u\right) \\
& \leq \gamma_{n} h d\left(T x_{n} T u\right)+\left(1-\gamma_{n}\right) d\left(T x_{n}, T u\right) \\
& \leq\left[1-(1-h) \gamma_{n}\right] d\left(T x_{n}, T u\right) .
\end{aligned}
$$

Again using (1.8),(2.5),(2.7) and Lemma 1.1(ii) [1], we have

$$
\begin{aligned}
d\left(T y_{n}, T u\right) & \leq d\left(\beta_{n} T S z_{n} \oplus\left(1-\beta_{n}\right) T x_{n}, T u\right) \\
& \leq \beta_{n} d\left(T S z_{n}, u\right)+\left(1-\beta_{n}\right) d\left(T x_{n}, T u\right) \\
& \leq \beta_{n} h d\left(T z_{n} T u\right)+\left(1-\beta_{n}\right) d\left(T x_{n}, T u\right) \\
& \leq \beta_{n} h\left[1-(1-h) \gamma_{n}\right] d\left(T x_{n} T u\right)+\left(1-\beta_{n}\right) d\left(T x_{n}, T u\right) \\
& \leq\left[1-(1-h) \beta_{n}-h(1-h) \beta_{n} \gamma_{n}\right] d\left(T x_{n}, T u\right) .
\end{aligned}
$$

Now using (1.8),(2.4),(2.8), $T S=S T$ (by assumption of the theorem) and Lemma 1.7(ii) [1], we have

$$
\begin{aligned}
& \quad d\left(T x_{n+1}, T u\right)=d\left(\alpha_{n} S T y_{n} \oplus\left(1-\alpha_{n}\right) T x_{n}, T u\right) \\
& \leq \alpha_{n} d\left(S T y_{n}, T u\right)+\left(1-\alpha_{n}\right) d\left(T x_{n}, T u\right) \\
& \leq \alpha_{n} h d\left(T y_{n}, T u\right)+\left(1-\alpha_{n}\right) d\left(T x_{n}, T u\right) \\
& \leq \alpha_{n} h\left[1-(1-h) \beta_{n}-h(1-h) \beta_{n} \gamma_{n}\right] d\left(T x_{n}, T u\right)+\left(1-\alpha_{n}\right) d\left(T x_{n}, T u\right) \\
& \leq\left[1-\left\{(1-h) \alpha_{n}-h(1-h) \beta_{n} \gamma_{n}+h^{2}(1-h) \alpha_{n} \beta_{n} \gamma_{n}\right\}\right] d\left(T x_{n}, T u\right) \\
& =\left(1-\beta_{n}\right) d\left(T x_{n}, T u\right),
\end{aligned}
$$

Where $\quad \beta_{n}=\left\{(1-h) \alpha_{n}-h(1-h) \alpha_{n} \beta_{n}+h^{2}(1-h) \alpha_{n} \beta_{n} \gamma_{n}\right\}, \quad$ since $0<h<\frac{m}{2}, m \geq 2, \quad$ and $\quad$ by assumption of the theorem $\quad \sum_{n=1}^{\infty} \alpha_{n}=\infty$, $\sum_{n=1}^{\infty} \alpha_{n} \beta_{n}=\infty, \sum_{n=1}^{\infty} \alpha_{n} \beta_{n} \gamma_{n}=\infty$, it follows that $\sum_{n=1}^{\infty} \beta_{n}=\infty$, therefore by Lemma 1.8 [1], we get that $\lim _{n \rightarrow \infty} d\left(T x_{n}, T u\right)=0$. Therefore $\left\{T x_{n}\right\}$ converges strongly to $T u$, where $u$ is the fixed point of the operator $S$ in $C$. This completes the proof. 


\subsection{Corollary 1}

Let $C$ be a nonempty closed convex subset of a complete $C A T(0)$ space. Let $S, T: C \rightarrow C$ be two commuting mappings such that $T$ is continuous, one-to-one, subsequentially convergent and $S: C \rightarrow C$ is T-Kannan contractive operator satisfying the condition

$$
d(T S x, T S y) \leq b\left[\frac{d(T x, T S x)+d(T y, T S y)}{m}\right],
$$

$\forall x, y \in X ; b \in\left(0, \frac{1}{m}\right), \forall m \geq 2$.

Let $\left\{T x_{n}\right\}$ be defined by the iteration scheme (1.8) [1]. If $\sum_{n=1}^{\infty} \alpha_{n}=\infty$, $\sum_{n=1}^{\infty} \alpha_{n} \beta_{n}=\infty$, and $\sum_{n=1}^{\infty} \alpha_{n} \beta_{n} \gamma_{n}=\infty$, then $\left\{T x_{n}\right\}$ converges strongly to Tu, where $u$ is the fixed point of the operator $S$ in $C$.

\subsection{Corollary 2}

Let $C$ be a nonempty closed convex subset of a complete CAT(0) space. Let $S, T: C \rightarrow C$ be two commuting mappings such that $T$ is continuous, one-to-one, subsequentially convergent and $S: C \rightarrow C$ is T-Chatterjea contractive operator satisfying the condition

$$
d(T S x, T S y) \leq c\left[\frac{d(T x, T S x)+d(T y, T S y)}{m}\right],
$$

$\forall x, y \in X ; c \in\left(0, \frac{1}{m}\right), \forall m \geq 2$.

Let $\left\{T x_{n}\right\}$ be defined by the iteration scheme (1.8) [1]. If $\sum_{n=1}^{\infty} \alpha_{n}=\infty$, $\sum_{n=1}^{\infty} \alpha_{n} \beta_{n}=\infty$, and $\sum_{n=1}^{\infty} \alpha_{n} \beta_{n} \gamma_{n}=\infty$, then $\left\{T x_{n}\right\}$ converges strongly to Tu, where $u$ is the fixed point of the operator $S$ in $C$.

\section{References}

1. A. Kirk, Geodesic Geometry and fixed point theory II , Proceedings of International Conference on Fixed Point Theory and Applications, Valencia (Spain), July 2003. 113-142.

2. W. A. Kirk, Geodesic Geometry and fixed point theory, in Seminar of Mathematical Analysis, Proccedings, Universities of Malaga and Seville (Spain), February 2003. 195-202 
Book of Proceedings

International Conference on Social Sciences, Humanities, and other sciences

3. M. Bridson and A. Haefliger, Metric Spaces of non positive curvature, Springer - Verlag, Berlin, Heidelberg, Neë York 1999. 3-176

4. Ismat Beg and Mujanid Abbas, Fixed point in CAT(0) spaces, January 2013. University of Central Punjab, Lahore, Pakistan and Lahore University of Management Sciences, Lahore, Pakistan.

5. Miroslav Bačák, Introduction to CAT(0) spaces, University of Newcastle 2010.

6. G. S. Saluja, Fixed point theorems for T-Ciric quasi-contractive operator in CAT(0) spaces. International Journal of Analysis and Applications. Volume 3, Number 1 (2013).

7. G.S.Saluja, Convergence Theorems for Generalized Asymptotically quasi-nonexpansive mappings in Banach. Journal of Nonlinear Functional Analysis 2014.

8. Ross Geoghegan and Pedro Ontaneda, Cocomact proper CAT(0) spaces, Febrary 1, 2008.

9. Kim Ruane, CAT(0) boundaries of truncated hyperbolic space, Septembre 13, 2004.

10. Hana Bennett,Christopher Mooney, and Ralf Spatzier, Affine maps between $\operatorname{CAT}(0)$ spaces, Septembre 4, 2013. Bradley University, Peoria, Ilinois.

11. W.A. Kirk, Fixed point theory in CAT(O) spaces and R-trees, Fixed Point and Applications, Vol. 2004, no.4, 309-316

12. K.S. Brown, Buildings, Springer, New York, NY, USA, 1989.

13. K. Goebel and S. Reich, Uniform convexity, hyperbolic geometry, and nonexpansive mappings, Vol. 83 of Monograph and Textbooks in Pure and Applied Mathematics, Marcel Dekker Inc., New York, NY, USA, 1984. 